\title{
Encyclopedia
}

\section{Transparent Solar Windows: From Labs to Industry, Towards Smart Cities}

Created by: Mohammad Nur E Alam

Revised by: Amber Yao

check for

Version received: 30 October 2019

updates

Many modern glass and window products are based on metal-dielectric coatings, which can control properties such as thermal emissivity, heat gain, colour, and transparency. These can also enable solar energy harvesting through PV integration, if the glazing structure is purposedesigned, to include luminescent materials and special microstructures. Recently, significant progress has been demonstrated in building integrated transparent solar windows, which are expected to add momentum towards the development of smart cities. These window systems are, at present in 2019, the only type of transparent and clear construction materials capable of providing significant energy savings in buildings, simultaneously with renewable energy generation.

The functionality of advanced nano-engineered optical functional materials and coatings and the demand for green energy generation makes the field of building integrated photovoltaics (BIPV) expand towards the opportunities of deploying transparent energy-harvesting windows. Metal-dielectric coatings of heat-mirror type can assist the collection of UV-blue and also the near-infrared solar energy and its re-distribution towards solar PV modules mounted at (or near) window panel edges. Futuristic "smart" construction practices have started to rely increasingly on providing the green energy harvesting functionalities needed for distributed energy generation in "smart cities". At present, the first commercial property-based field trials of these technologies are starting to happen.

Here we summarize our research and development record of accomplishment in the field of solar windows development, at Edith Cowan University (ECU, Australia). We have designed, prototyped, and characterized the various components, technologies, and opto-electronic systems used in solar windows, at our nanofabrication labs in cooperation with Clearvue Technologies Ltd. (Perth, Australia). 

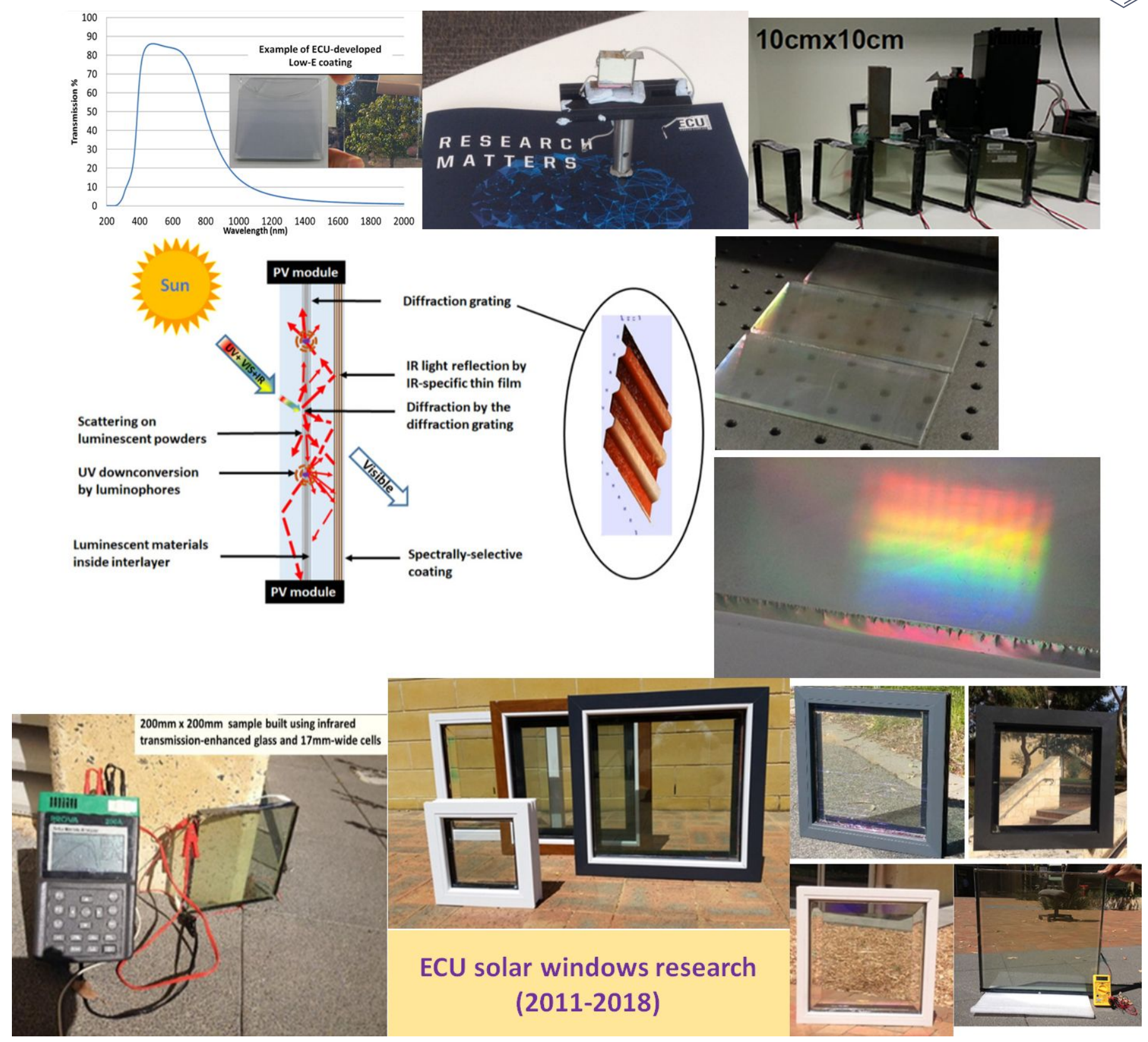

Figure 1. A principal diagram of solar window development milestones demonstrated by ECU research team.

A significant number of research results in the areas related to the practical development of all relevant components and systems optimized to work within the structure of transparent all-inorganic solar windows have been reported in $[\underline{1}][\underline{2}][\underline{3}][\underline{4}][\underline{5}]$. The current status of BIPV products development and modern trends in solar windows have been reviewed comprehensively in [].

The emergent applications of transparent solar windows in buildings and other smart-city infrastructure objects are outlined in Fig. 2, which also shows a photo of the newly installed shopping mall atrium at Warwick Grove Shopping Centre in Perth, fitted with 18 solar windows. These windows contained several of the principal design features prototyped previously at ECU. 


\section{Encyclopedia}

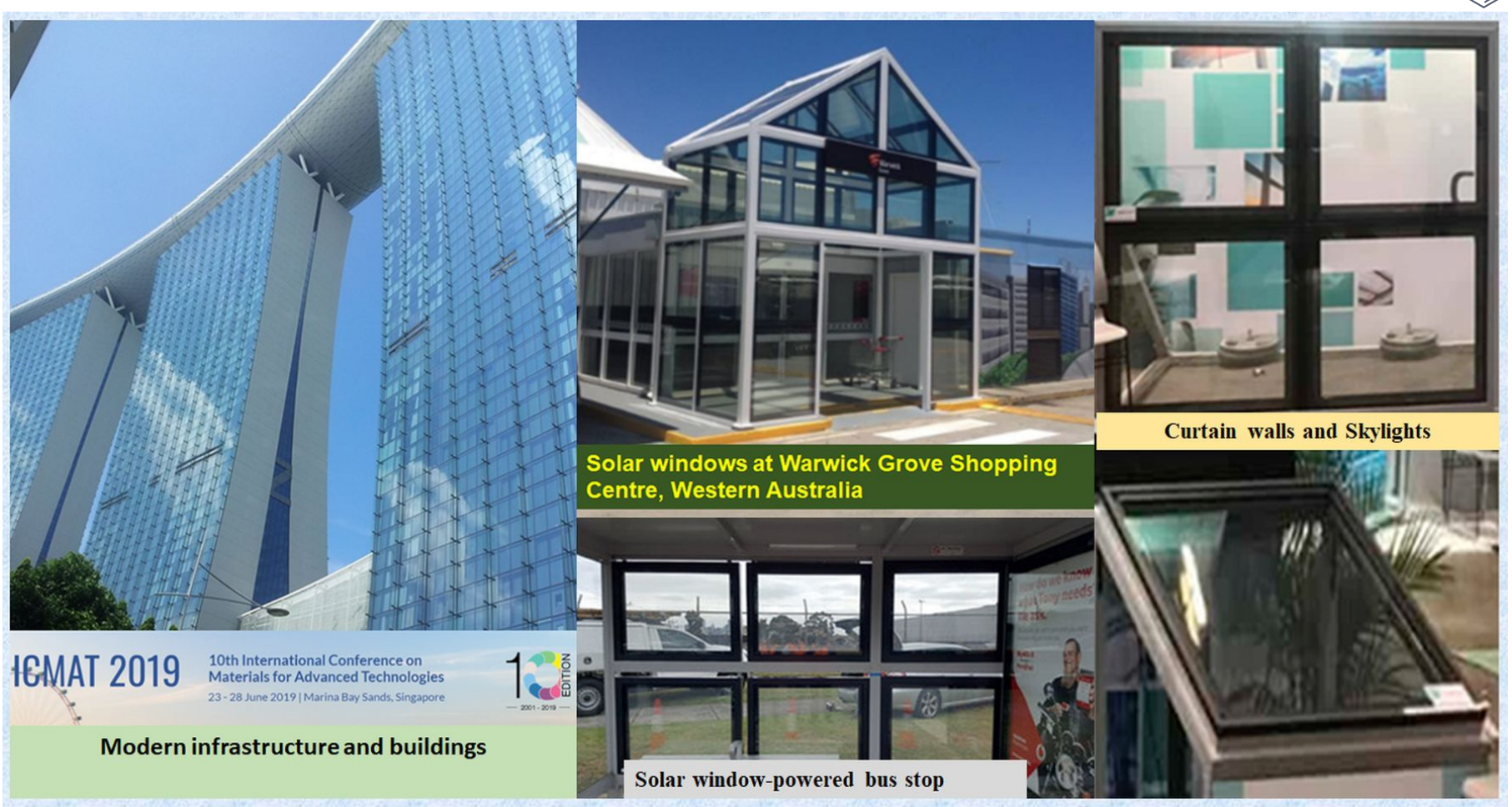

Figure 2. Current and future application areas of transparent solar windows.

A brief summary of the main power generation and energy production results measured from the Warwick Grove installation is provided in Fig. 3. The live measured data broadcast is available from http://tcp.iotstream.io/vicinity-warwickgrove/index.php. 


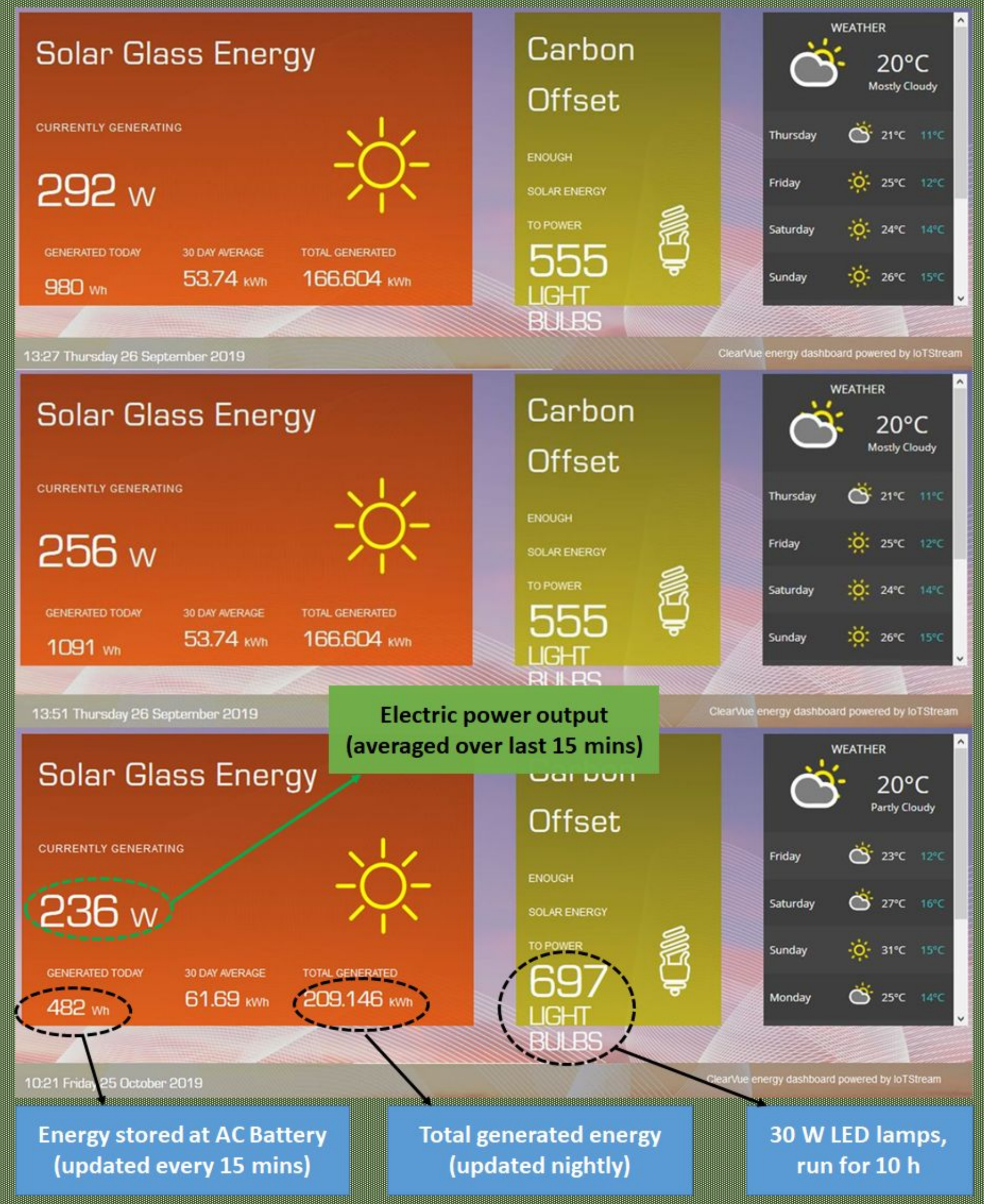

Figure 3. A summary of solar window installation performance (18 windows) monitored at Warwick Grove Shopping Centre (Perth, Australia).

The detailed results of this pilot trial of solar windows, together with the modelled predictions and the various power generation datasets are available from Ref. [7]; we first reported the commencement of this world-first field trial at ICMAT 2019 (Ref. [ ${ }^{8}$ ), among other material system development results related to solar control coatings.

Acknowledgement: The authors would like to acknowledge the research contributions of Dr. Yamna El 
Moudden, Dr. Ramzy Alghamedi, and Dr. Mohsin Ali Badshah, made during the various stages of our research journey.

\section{References}

1. El Mouedden, Y.; Alghamedi, R.; Nur-E-Alam, M.; Vasiliev, M.; Alameh, K. Thin film coatings for solar and thermal radiation control prepared by physical vapour deposition. In Proc., of the 9th International Conference on High Capacity Optical Networks and Enabling Technologies (HONET) 2012, Istanbul, Turkey,12-14 December 2012.

2. Alghamedi, R.; Vasiliev, M.; Nur-E-Alam, M.; Alameh, K.; Spectrally-selective all-inorganic scattering luminophores for solar energy-harvesting clear glass windows. Sci. Rep., 2014, 4, 6632, 10.1038/srep06632.

3. Vasiliev, M.; Alghamedi, R.; Nur-E-Alam, M.; Alameh, K.; Photonic microstructures for energy-generating clear glass and net-zero energy buildings. Sci. Rep., 2016, 6, 31831, 10.1038/srep31831.

4. Vasiliev, M.; Alameh, K.; Badshah, M. A.; Kim, S. E.; Nur-E-Alam, M.; Semi-transparent energy-harvesting solar concentrator windows employing infrared transmission-enhanced glass and large-area microstructured diffractive elements. Photonics 2018, 5, 25, 10.3390/photonics5030025.

5. Vasiliev, M.; Alameh, K.; Nur-E-Alam, M.; Spectrally-selective energy-harvesting solar windows for public infrastructure applications. Appl. Sci., 2018, 8, 849, 10.3390/app8060849.

6. Vasiliev, M.; Nur-E-Alam, M.; Alameh, K.; Recent developments in solar energy-harvesting technologies for building integration and distributed energy generation. Energies 2019, 12, 1080, 10.3390/en12061080.

7. Vasiliev, M.; Nur-E-Alam, M.; Alameh, K.; Initial field testing results from building-integrated solar energy harvesting windows installation in Perth, Australia. Appl. Sci., 2019, 9, 4002, 10.3390/app9194002.

8. Vasiliev, M.; Nur-E-Alam, M.; Alameh, K. Highly stable thin-film coating materials and multilayers for thermal regulation and energy saving applications. Symposium: P, Advanced Inorganic Materials and Thin Film Technology for Solar Energy Harvesting and Electronic Application, Presentation ID: 190023, In Proc., ICMAT 2019, Marina Bay Convention Center, June 23-28, 2019, Singapore; https://www.conftool.pro/icmat2019/index.php? page $=$ browseSessions\&form_session $=853 \#$ paperID190023

\section{Keywords}

renewables; energy saving and generation; built environments; solar windows; advanced glazings; photovoltaics

(C) 2019 by the author(s). Distribute under a Creative Commans CC BY license 